\title{
RESIN KEY HANGER MAKING TRAINING IN EFFORTS TO IMPROVE ECONOMIC INDEPENDENCE FOR TARUNA CORAL, SUKAKARYA VILLAGE, MEGAMENDUNG SUB- DISTRICT, BOGOR DISTRICT
}

\author{
Amalina Shomami ${ }^{1}$, Mochammad Sholeh ${ }^{2}$ \\ Prodi Manufaktur, Jurusan Teknik Mesin \\ E-mail: amalina.shomami@mesin.pnj.ac.id ; moch.sholeh@mesin.pnj.ac.id
}

\begin{abstract}
Community service activities for the 2019 D IV Manufacturing Study Program are motivated by the cultural conditions of the community that have not prioritized education as a means of supporting economic independence and the community's need for technical training following village potential. The current condition, most of the residents of Sukakarya village are casual workers and ojeg workers, even though these jobs cannot provide economic independence, and their income is still minimal. The priority of this training is to increase insight into the importance of education and skills of young people in making critical chains with resin media. This training method is discussion and practice. Meetings were held in an effort to open up insights that education is essential. After that, the process of learning the way of making key hanging made from the resin was carried out, which was guided by the lecturers and students. This training facility includes rooms, module equipment, tools, and critical materials, trainers consisting of lecturers and students, transportation, and consumption. The purpose of this community service, in general, is the socialization of the importance of education so that it is expected to be able to change the perspective of the community. Besides, it also increases simple technical skills, namely the manufacture of resin key hanging.
\end{abstract}

Keywords: Training, key chains, resin, youth

\section{PELATIHAN PEMBUATAN GANTUNGAN KUNCI BERBAHAN RESIN DALAM UPAYA PENINGKATAN KEMANDIRIAN EKONOMI UNTUK KARANG TARUNA DESA SUKAKARYA, KECAMATAN MEGAMENDUNG, KABUPATEN BOGOR}

\begin{abstract}
ABSTRAK Kegiatan pengabdian masyarakat Program Studi D IV Manufaktur 2019 dilatarbelakangi oleh kondisi budaya masyarakat yang belum memprioritaskan pendidikan sebagai saran penunjang kemandirian ekonomi dan kebutuhan masyarakan akan pelatihan keteknikan yang sesuai dengan potensi desa. Kondisi saat ini sebagian besar penduduk desa Sukakarya adalah buruh lepas dan tukang ojeg, padahal pekerjaaan tersebut tidak dapat memberikan kemandirian ekonomi dan penghasilan yang masih minim. Prioritas pelatihan ini adalah meningkatan wawasan pentingnya pendidikan dan keterampilan pemuda-pemudi dalam membuat gantungan kunci dengan media resin. Metode pelatihan ini adalah diskusi dan praktek. Diskusi dilakukan dalam upaya membuka wawasan bahwa pendidikan itu penting. Setelah itu dilakukan proses pembelajaran praktek pembuatan gantungn kunci berbahan resin yang dibimbing oleh para dosen dan mahasiswa. Fasilitas pelatihan ini meliputi ruangan, perangkat modul, alat dan bahan gantunan kunci, trainer terdiri dari dosen dan mahasiswa, transportasi, dan konsumsi. Tujuan pengabdian masyarakat ini secara umum adalah sosialisasi pentingnya pendidikan sehingga diharapkan mampu mengubah cara pandang masyarakat. Selain itu juga peningkatkan keterampilan teknik sederhana, yaitu pembuatan ganrungan kunci berbahan resin.
\end{abstract}

Kata Kunci : Pelatihan, gantungan kunci, resin, pemuda-pemudi 


\section{PENDAHULUAN}

Desa Sukakarya terdiri dari $5 \mathrm{RW}$ dan 23 RT. Luas wilayah desa \pm 333 ha dengan jumlah penduduk \pm 7000 penduduk. Lokasi desa ini tidak jauh dari pintu tol keluar Gadog, desa ini juga dekat dengan 2 tempat wisata; Taman Safari dan Taman Matahari. Mata pencaharian penduduk: Buruh harian lepas (buruh bangunan harian, petani penggarap) dan tukang Ojeg.

Terdapat 7 Bengkel motor kecil (Isi angin, Tambal / ganti ban, ganti velg) di Desa Sukakarya dengan tidak ada keahlian dibidang teknik pada awalnya. Mereka dulunya bekerja di bengkel, yang kemudian membuka secara mandiri di rumah-rumah.

Penduduk di desa ini umumnya $( \pm$ $50 \%$ memiliki pendidikan terakhir setingkat SMP - SMA. Lulus SMA hampir tidak ada yang melanjutkan ke tingkat Perguruan tinggi, umumnya selepas SMA langsung menikah. Bagi penduduk yang tidak lulus SMA/SMK, mereka umumnya bekerja sebagai buruh harian lepas atau menjadi tukan gojeg. Hal yang tidak jauh berbeda juga terjadi pada penduduk yang lulus SMA/SMK dan menikah. Karena minim keahlian dan tekad untuk berjuang, penduduk ini juga berakhir sebagai buruh harian lepas maupun tukan gojeg. Terdapat 2 wadah sebagai sarana warga dalam hal ini adalah karang taruna dan eco village.

Desa Sukakarya belum pernah mendapatkan pelatihan keahlian keteknikan seperti ini, sehingga pihak desa sangat menyambut baik niatan PNJ khususnya Prodi Manufaktur untuk mengadakan Pelatihan pembuatan souvenir dengan media resin ini.Tujuaannya agar remaja maupun warga desa dapat berinovasi dalam berkarya khususnya pada souvenir. Sehingga dapat meningkatkan taraf hidup serta kesejahteraan warga desa.

Pihak desa merasa bahwa masyarakat desa Sukakarya ini sangat sulit untuk dirubah pola pikirnya, serta tidak memiliki tekad untuk berjuang mengubah kondisi kehidupannya, terutama dibidang kesejahteraan. Hal ini terbukti dengan pola "tamat sekolah-menikah-menjadi buruh harian lepas/ojeg- memiliki anak - tidak ada biaya untuk kuliah-dst".

Untuk itu pihak desa mengharapkan dengan adanya pelatihan ini dapat mengubah pola piker masyarakat desa agar menjadi lebih mandiri, dan memiliki pola pikir yang lebih maju.

\section{METODE PENELITIAN}

Metode yang digunakan dalam pengabdian ini menggunakan pendekatan participant active learning (peserta berpartisipasi secara aktif dalam kegiatan pelatihan dan pendampingan proses pembuatan gantungan kunci berbahan resin). Selanjutnya, dalam proses pelatihan dan pendampingan ada interaksi dua arah sehingga memberikan kesempatan instruktur dan peserta untuk menyumbangkan ide, pendapat, pikiran dan pengalamannya. Adapun metode yang digunakan dalam proses pelatihan dan pendampingan ini adalah ceramah, tanya jawab, diskusi, curah pendapat, studi kasus dan praktik. Pengertian masing-masing metode yang digunakan dijelaskan berikut :

1) Metode ceramah digunakan untuk menyampaikan materi pelatihan, seperti : menjelaskan bagaimana tentang sistem proyeksi gambar

2) Metode tanya jawab merupakan suatu cara penyampaian materi untuk pelatihan yang dilakukan dengan tujuan memberikan kejelasan suatu informasi/ pengetahuan dan konsep dengan cara mengajukan pertanyaan dan dijawab oleh pihak lain.

3) Metode diskusi adalah kegiatan yang dilakukan dengan melibatkan peserta pelatihan dan pendampingan dalam membahas dan memecahkan permasalahan yang ditugaskan dalam kegiatan pelatihan dan pendampingan sehingga ada kegiatan 
saling bertukar pikiran terkait ide dan gagasan masing-masing untuk kemudian melahirkan kesepakatan bersama.

4) Metode curah pendapat digunakan untuk mengetahui pendapat peserta pelatihan dan pendampingan terhadap suatu permasalahan.

5) Metode studi kasus digunakan untuk membahas suatu kasus/permasalahan yang spesifik dan diperlukan pemecahannya.

6) Praktik merupakan kegaiatan yang dilakukan peserta pelatihan dan pendampingan dimana peserta melakukan praktik secara langsung dalam pendampingan pengaplikasian komputer dengan arahan fasilitator.

7) Angket merupakan instrumen penelitian berupa kuisioner. Kuisioner diberikan setelah pelatihan (post test). Untuk menetapkan keabsahan data diperlukan kriteria pemeriksaan data berupa kriteria derajat kepercayaan. Hal ini dilakukan untuk menjaga kredibilitas hasil pelatihan yang dilakukan. Validasi yang digunakan untuk menjaga kredibilitas ini adalah triangulasi. Analisis data dilakukan melalui tiga jalur kegiatan yang berjalan secara simultan. Ketiga jalur tersebut adalah (1) reduksi data, yakni proses pemilihan, pemusatan, perhatian pada penyederhanaan, pengabstrakan, dan transformasi data kasar yang muncul dari catatancatatan tertulis di lapangan; (2) penyajian data, yakni penyajian informasi yang telah tersusun yang kemungkinan memberikan penarikan kesimpulan dan pengambilan tindakan; dan (3) penarikan kesimpulan/verifikasi

\section{HASIL DAN PEMBAHASAN}

Pengabdian ini dilaksanakan di Wisma Lenteng Agung yang terletak di
Desa Sukakarya, Kecamatan Megamendung, Kabuptan Bogor. Kegiatan pelatihan dan pendampingan dalam pembuatan gantungan kunci berhabah resin dalam upaya peningkatan kemandirian ekonomi untuk Karang taruna Des Sukakarya, Kec Megamendung, Kec Bogor merupakan pendampingan yang sangat diperlukan bagi karang taruna dalam rangka peningkatan wawasan dan keterampilan peserta sehingga menumbuhkan minat untuk berwiraswasta dalam bidang kerajinan tangan tersebut.

Kegiatan penumbuhan minat meningkatkan diri ini juga disertai dengan pemberian penyuluhan tentang akan pentingnya pendidikan yang saat ini mereka tinggalkan. Umumnya masyarakat sekolah hanya sampai SMP atau setingkat SMA yang kemudian jika sudah memiliki penghasilan langsung menikah meskipun usia masih muda, juga penumbuhan keberanian untuk keluar daerah untuk meningkatkan taraf kehidupan

Hasil yang dicapai dalam kegiatan ini, secara garis besar terdiri atas : 1) pra kegiatan, 2) tahap perencanaan kegiatan, 3) tahap pelaksanaan kegiatan pelatihan, 4) tahap follow up kegiatan pelatihan dalam bentuk pendampingan pengaplikasian, dan penyuluhan pentingnya pendidikan, 5) tahap evaluasi kegiatan. Adapun kegiatan yang telah dilaksanakan adalah sebagai berikut.

Pada tahap ini tim pengabdian melakukan kegiatan survey yang dilakukan pada tgl 21 Maret 2019 untuk menggali keadaan Desa Sukakarya, bidang apa yang perlu diadakan pengabdian.

Dari survey ini dilakukan pembicaraan dengan Sek-Des tentang pelaksanaan Pengabdian Kepada Masyarakat, oleh Bapak Iyus Alex sebagai Sek-Des disambut dengan baik, dan bersedia untuk mengumpulkan peserta pelatihan sejumlah 40 orang.

Selanjutnya dibuatkan perjanjian kesediaan sebagai tuan rumah untuk 
pelaksanaan Pengabdian Kepada Masyarakat ini.

Pada tahap perencanaan tim pengabdian masyarakat membuat rencana dan rancangan dengan melakukan kegiatan sebagai berikut :

a) Studi proses pembuatan gantungan kunci berbahan resin dan analisis kebutuhan berdasarkan fakta lapangan guna menentukan rancangan desain kegiatan pembelajaran.

b) Perencanaan Ipteks (materi pelatihan dan pendampingan) yang akan diberikan kepada peserta nantinya. Rancangan materi pelatihan dan pendampingan ini terdiri dari: Cara membuat cetakan menggunakan Rubber Silikon dan cara membuat gantungan kunci sesuai cetakan yang telah dibuat.

c) Pembuatan materi pelatihan proses pembuatan cetakan dengan Rubber silicon dan pembuatan gantungan kunci berbahan resin serta pemasangannya ke gantungan.

Sebelum kegiatan Pelatihan Pembuatan Gantungan Kunci Berbahan Resin Dalam Upaya Peningkatan Kemandirian untuk Karang Taruna Desa Sukakarya, Kec. Mega Mendung, Kab. Bogor ini dimulai, tim pengabdian dibantu oleh mahasiswa memandu peserta untuk mengisi daftar hadir dan membagikan modul pelatihan

Adapun pemilihan untuk pelatihan ini diharapkan nantinya peserta akan mengembangkan dirinya sehingga mampu membuat gantungan kinci atau bentuk souvenir lain berbahan baku resin untuk meningkatkan perekonomiannya.

Peserta takkan bisa mengembangkan diri tanda diberikan penyadaran pentingnya pendidikan dan materi ini disampaikan dengan maksud agar generasi selanjutnya di Desa Sukakarya ini akan mendapatkan pendidikan yang lebih baik sehingga taraf kehidupan masyarakat akan meningkat.
Tahap tindak lanjut kegiatan pelatihan pembuatan Gantungan Kunci Berbahan Resin dilakukan dalam bentuk pendampingan praktik pembuatan cetakan menggunakan Rubber Silikon. Perbandingan antara Rubber Silikon dengan hardener volume Hardener 5\% dari silikon Ruber.

Silikon rubber ada 2 type RTV 585 dan 586 tergantung hasil cetakan yang dihasilkan, kaku dan lemes. Setelah cetakan terbentuk baru mengaduk resin yang dicampur denga hardener untuk dijadikan hiasan pada gantungan kunci.

Produk hasil pelatihan dan pendampingan berupa kemampuan dalam membuat cetakan dan membuat hiasan gantungan kunci dengan variasinya.

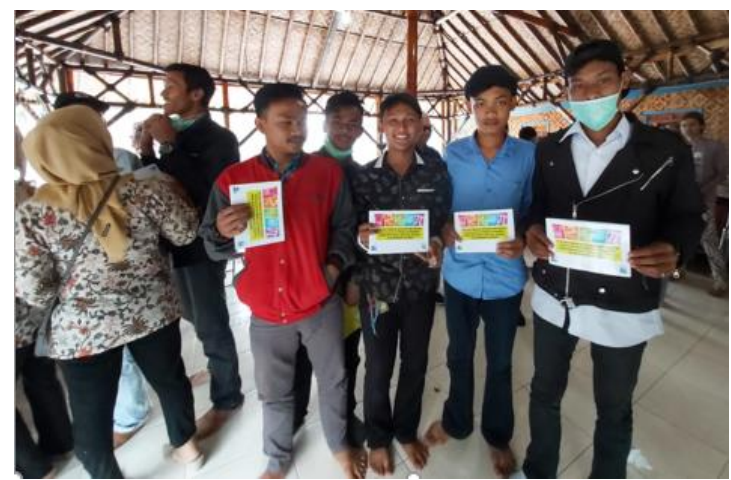

Foto No.1 Peserta dengan modul pelatihan

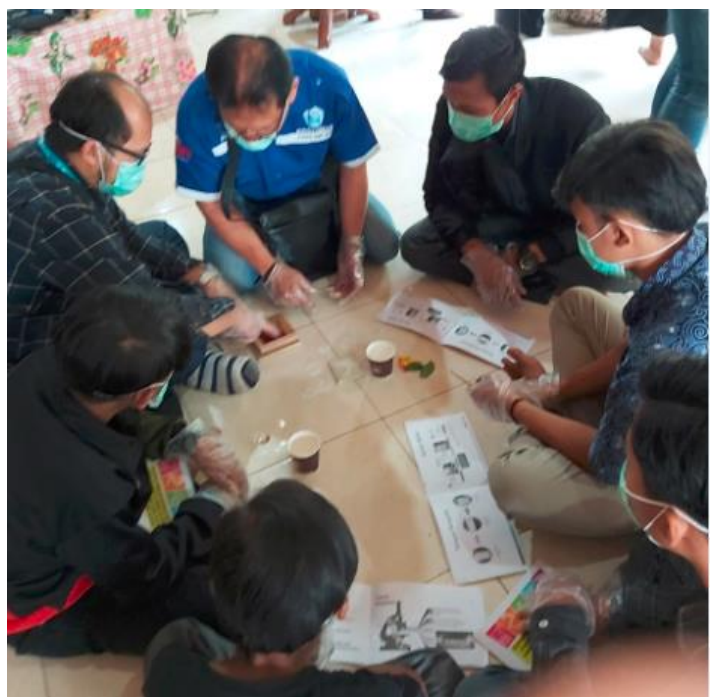

Foto No. 2. Keseriusan Peserta Dalam Pelatihan didampingi Dosen 
Tim pengabdian melakukan kegiatan evaluasi, menilai, memberi saran, masukan dan penghargaan terkait hasil pelatihan dan produk pelatihan yang dilakukan dan dibuat oleh peserta pengabdian.

\section{Pemahaman Proses Pembuatan}

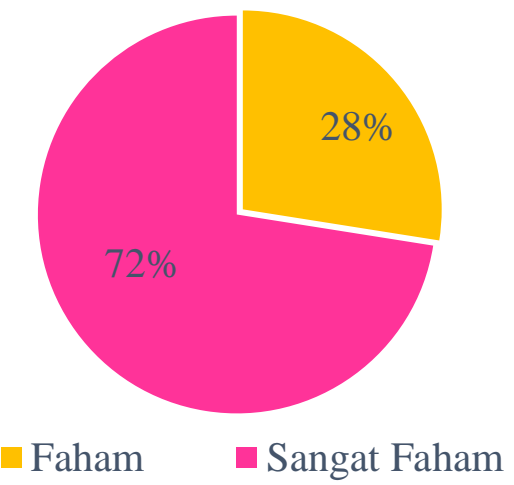

Gambar 1. Bagan Pemahaman Proses Pembuatan

Dari hasil evaluasi (gambar 1) yang didapat melalui data kuisioner yang diberikan setelah pelatihan kepada 40 peserta, diperoleh data bahwa kemampuan peserta dalam memahami proses pembuatan cetakan ataupun hiasan gantungan kunci yaitu $72 \%$ sangat memahami dan $28 \%$ paham, $0 \%$ untuk Cukup paham dan 0\% untuk Kurang paham.

Tidak ada peserta yang menyatakan cukup paham apalagi kurang paham dalam pemberian materi pelatihan.

\section{Bimbingan Dalam Pelatihan}

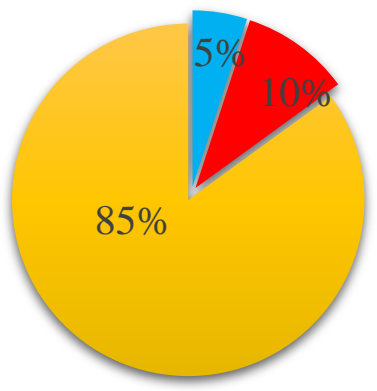

-Sedang —Cukup $\square$ Mudah
Gambar 2. Bagan Bimbingan dalam Pelatihan

Hal terpenting lainnya dalam sebuah kegiatan pelatihan adalah perlunya pembimbing/instruktur pelatihan yang mumpuni dalam memberikan materi pelatihan. Pada pengabdian masyarakat ini, Program Studi Manufaktur Jurusan Teknik Mesin Politeknik Negeri Jakarta didukung oleh dosen-dosen yang andal dalam bidangnya, sehingga yang disampaikan bisa diterima dengan baik. Hal tersebut terlihat pada gambar 2, dari data yang kami peroleh dari hasil kuisioner yang diberikan sesaat setelah pelatihan. Sebanyak 85\% peserta mengaku mudah mengerti dengan arahan yang diberikan oleh pembimbing/instruktur, $10 \%$ siswa peserta menyatakan cukup mudah dimengerti. Meskipun masih terdapat 5\% peserta masih sedang dalam menangkap isi materi yang disampaikan, akan tetapi dari angka-angka persentasi tersebut menunjukkan respon yang positif dari siswa peserta pelatihan.

Isi dan Metoda Pelatihan

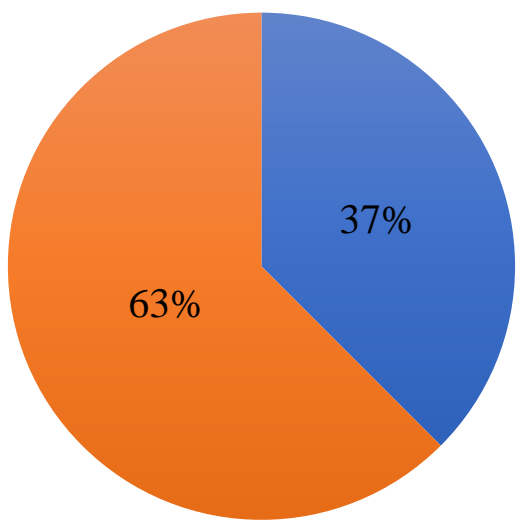

- Memuaskan Cukup Memuaskan

Gambar 3. Bagan Isi dan Metoda Pelatihan

Disini ditanyakan tentang isi dan metode pelatihan yang diberikan oleh instruktur dalam pelatihan apakah mudah dimengerti? 
Ada 4 alternatif jawaban, Memuaskan, Cukup memuaskan, Kurang memuaskan dan Tidak Memuaskan

Selain peran pembimbing/instruktur pelatihan, isi dan metode pelatihan pun turut berperan penting dalam kelancaran kegiatan pelatihan ini. Isi menyangkut pada modul/materi yang disampaikan, isinya harus sesuai dengan maksud dan tujuan. Metode yang digunakan dalam pelatihan ini pun harus mampu menciptakan suasana belajar yang kondusif. Jika dilihat dari hasil kuisioner yang kami bagikan kepada 40 peserta pelatihan, sebanyak $63 \%$ peserta mengatakan bahwa isi dan metode yang dipakai dalam kegiatan pelatihan ini memuaskan, serta $37 \%$ peserta pelatihan mengatakan cukup memuaskan.

$$
\text { Berdasarkan angka-angka }
$$

persentase yang telah dihitung dari kuisioner tersebut, maka dapat disimpulkan bahwa peserta merasa puas dan mengatakan kegiatan pelatihan ini sangat bermanfaat bagi Karang Taruna seperti mereka. Secara keseluruhan kegiatan Pelatihan Pembuatan Gantungan Kunci Berbahan Resin Dalam Upaya Peningkatan Kemandirian untuk Karang Taruna Desa Sukakarya, Kec. Mega Mendung, Kab. Bogor berjalan dengan lancar, aktif, kreatif, efektif dan menyenangkan.

\section{SIMPULAN}

Hasil yang dicapai melalui kegiatan pelatihan pembuatan gantungan kunci berbahan resin Dalam upaya peningkatan kemandirian ekonomi untuk Karang taruna Desa sukakarya, kec. Megamendung, kab. Bogor

1) Peserta memiliki sudut pandang dalam meningkatkan kemandirian ekonomi

2) Peserta dapat membuat gantungan kunci atau bentuk souvenir lain yang bisa dijual guna meningkatkan perekonomiannya.
3) Peserta diharapkan bisa memiliki kesadaran akan pentingnya pendidikan guna meningkatkan mutu diri sehingga mampu meningkatkan perekonomian.

Beberapa saran yang bisa disampaikan adalah sebagai berikut:

a. Peserta agar senantiasa berupaya secara terus menerus mengembangkan kemampuan profesionalismenya melalui berbagai kegiatan pelatihan khususnya di bidang teknik;

b. Peningkatan pendidikan senantiasa dilakukan baik dibidang keduniaan ataupun dibidang keagamaan dan agar terus diaplikasikan secara berkesinambungan. 